\title{
SUBCRITICAL NONLINEAR PSEUDODIFFERENTIAL EQUATION OF SOBOLEV TYPE ON A HALF-LINE
}

\section{Elena I. Kaikina And Hector F. Ruiz PAREDES}

Abstract. We study the initial- boundary value problem for the complex pseudodifferential equation of Sobolev type on a half-line

$$
\left\{\begin{array}{c}
\partial_{t} u+\lambda|u|^{\sigma} u+\mathbb{K} u=0, x \in \mathbb{R}^{+}, t>0, \\
u(0, x)=u_{0}(x), x \in \mathbb{R}^{+},
\end{array}\right.
$$

where $0<\sigma<1, \lambda \in \mathbb{C}$,

$$
\mathbb{K} u=\frac{1}{2 \pi i} \int_{-i \infty}^{i \infty} e^{p x} K(p) \widehat{u}(t, p) d p .
$$

the symbol $K(p)$ is defined as

$$
K(p)=(-1)^{n+1} p^{2 n} \prod_{j=1}^{n}\left(p^{2}-a_{j}^{2}\right)^{-1},
$$

$n \in N, \operatorname{Re} a_{j}>0, j=1,2 \ldots, n, \theta(x) .$. The aim of this paper is to prove the global existence of solutions to the inital-boundary value problem and to find the main term of the asymptotic representation of solutions in the subcritical case,when the nonlinear term of the equation has the time decay rate less then that of the linear terms.

Mathematics subject classification (2010): 35Q35, 35Q40.

Keywords and phrases: initial-boundary value problem, global existence, asymptotics, pseudodifferential equation.

\section{REFERENCES}

[1] M. Escobedo, O. KAVIAN, Asymptotic behavior of positive solutions of a non-linear heat equation, Houston Journal of Mathematics 13 (1987),39-50.

[2] A. GMira, L. Veron, Large time behavior of the solutions of a semilinear parabolic equation in $\mathbb{R}^{n}$, J. Diff. Eqs. 53 (1984), 258-276.

[3] G.V. Demidenko, S.V. UsPensKiI, Equations and systems that are not solved with respect to the highest derivative, Nauchnaya Kniga, Novosibirsk, 1998, 437 pp.

[4] I.E. Egorov, S.G. Pyatkov, S.V. Popov, Nonclassical operator-differential equations, Nauka, Novosibirsk, 2000, $336 \mathrm{pp}$.

[5] A. Favini, A. YAGi, Degenerate differential equations in Banach spaces, 215, Marcel Dekker, Inc., New York, 1999, 313 pp.

[6] N. Hayashi, E.I. KaIKINA, Nonlinear Theory of Pseudodifferential Equations on a Half-Line, North-Holland Mathematics Studies, 194, 340 p, 2004.

[7] N. Hayashi, E.I. Kaikina, P.I. Naumkin, I. Shishmarev, A. Asymptotics for dissipative nonlinear equations. Lecture Notes in Mathematics, 1884. Springer-Verlag, Berlin, 2006, 557 pp.

[8] E.I. KaIKInA, Subcritical nonlinear nonlocal equations on a half-line, J. Math. Anal. Appl., 305 (2005), 316-346.

[9] E.I. KAIKINA, Subcritical Kuramoto-Sivashinsky-type equation on a half-line, J. Differential Equations, 220 (2006), 279-321. 
[10] G. KARCH, Asymptotic behavior of solutions to some pseudoparabolic equations, Mat. Meth. in the Applied Sciences, 20 (1997), 271-289.

[11] O. KaVIAN, Remarks on the large time behavior of a nonlinear diffusion equation, Ann. Inst. Henri Poincaré, Analyse non linéaire, 4, No. 5 (1987), 423-452.

[12] A.G. Sveshnikov, A.B. Al'shin, M.O. Korpusov, Yu.D. Pletner, Linear and nonlinear equations of Sobolev type, (FIZMATLIT, Moscow, 2007), pp. 734.

[13] R. Prado, E. ZuAzuA, Asymptotic expansion for the generalized Benjamin-Bona-Majoni-Burgers equation, J. Diff. Int. Eq.,15 (2002), 1409-1434.

[14] R.E. ShOWALTER, Monotone operators in Banach space and nonlinear partial differential equations, 49, American Mathematical Society, Providence, RI, 1997, 278 pp.

[15] U. STEFANELLI, On a class of doubly nonlinear nonlocal evolution equations, Differential Integral Equations, 15 (2002), 897-922.

[16] G.B. Whitham, Linear and Nonlinear Waves, Wiley, N.Y., 1974. 